\title{
SINALIZAÇÕES DAS ESCOLAS E MUNICÍPIOS NO CONTEXTO DO IDEB 2019: TENTATIVA PRELIMINAR DE LEITURA DO IDEB-2019
}

\author{
SEÑALES DE ESCUELAS Y MUNICIPIOS EN EL CONTEXTO DE IDEB 2019: \\ INTENTO PRELIMINAR DE LEER IDEB-2019
}

\author{
SIGNALING OF SCHOOLS AND MUNICIPALITIES IN THE CONTEXT OF IDEB \\ 2019: PRELIMINARY ATTEMPT TO READ IDEB-2019
}

RESUMO: Elaboramos uma análise preliminar do Ideb 2019, aproveitando seu lançamento nessa terceira semana de setembro de 2020 (INEP/MEC, 2020. Ideb, 2020). Vamos focar o comportamento de MS, até onde possível e comparativamente. Algumas indicações já foram anotadas, como um avanço no EM de 2017 para 2019, talvez por conta da Reforma do EM que, mesmo mantendo o mesmo instrucionismo, mexeu com o sistema. Alguns estados se destacaram, tendo agora o Ceará um grande rival, Goiás, e preconizando a importância da movimentação municipal e local. Note-se, porém, que o avanço recente chama a atenção porque o EM mostrava, na série histórica, leseira já marcada; em si, o avanço foi pequeno e está muito longe da solicitação da BNCC de "recriação da escola".

PALAVRAS-CHAVE: IDEB. Educação. Escola. BNCC.

RESUMEN: Preparamos un análisis preliminar de Ideb 2019, aprovechando su lanzamiento en la tercera semana de septiembre de 2020 (INEP/MEC, 2020. Ideb, 2020). Me centraré en el comportamiento de Mato Grosso do Sul, en la medida de lo posible y comparativamente. Ya se han observado algunos indicios, como el avance de la enseñanza secundaria de 2017 a 2019, tal vez debido a la reforma de la enseñanza secundaria, que, aunque mantiene la misma instrucción, ha alterado el sistema. Algunos estados se destacaron, siendo Ceará ahora un gran rival, Goiás, y defendiendo la importancia del movimiento municipal y local. Cabe señalar, sin embargo, que el reciente avance llama la atención porque la escuela secundaria mostró, en la serie histórica, una lesión ya marcada; en sí mismo, el avance fue pequeño y está muy lejos de la petición de la BNCC de "recrear la escuela".

PALABRAS CLAVE: IDEB. Educación. Colegio. BNCC.

\footnotetext{
${ }^{1}$ Universidade de Brasília (UnB), Brasília - DF - Brasil. Professor Emérito. Doutor em Sociologia pela Universidade do Sarre - Alemanha. Bolsista Produtividade 1B CNPq. ORCID: https://orcid.org/0000-00025514-2781. E-mail: lepp@rc.unesp.bre

${ }^{2}$ Centro Universitário do Sul de Minas (UNIS), Varginha - MG - Brasil. Pesquisador Titular no Departamento de Pesquisa. Doutor em Educação Escolar (UNESP). ORCID: https://orcid.org/0000-0003-1171-217X. E-mail: r.silva@unesp.br
} 
ABSTRACT: A preliminary analysis of Ideb 2019 was carried out, taking advantage of its launch in the third week of September 2020 (INEP/MEC, 2020. Ideb, 2020). We will focus on the behavior of Mato Grosso do Sul, as far as possible and comparatively. Some indications have already been noted, such as an advance in high school from 2017 to 2019, perhaps because of the High School Reform, which, while maintaining the same instruction, has messed with the system. Some states stood out, with Ceará now having a great rival, Goiás, and advocating the importance of municipal and local movement. It should be noted, however, that the recent advance draws attention because the high school showed, in the historical series, the already known delay; in itself, the advance was small and is very far from the request of the BNCC to "recreate the school".

KEYWORDS: IDEB. Education. School. BNCC.

\section{Introdução}

É possível ler no Ideb-2019 um recado da base escolar e municipal, que já vinha se prenunciando em períodos anteriores, como nos resultados de municípios cearenses, com destaque histórico para Sobral (DEMO, 2017): educação se conduz melhor local ou municipalmente. Sobral, pelos dados de 2019, ocupa o $11^{\circ}$ lugar para o $5^{\circ}$ ano do Ensino Fundamental (EF) e o $10^{\circ}$ para o $9^{\circ}$ ano do $\mathrm{EF}^{3}$. Era ainda o município mais populoso (mais de 200 mil habitantes) nesse grupo de municípios.

Quadro 1 - Ranking dos melhores municípios no IDEB-2019, $5^{\circ}$ ano do EF e $9^{\circ}$ ano do EF

\begin{tabular}{|c|c|c|c|c|c|c|c|c|c|}
\hline \multicolumn{5}{|c|}{$5^{\circ}$ ano do EF } & \multicolumn{5}{|c|}{$9^{\circ}$ ano do EF } \\
\hline Posição & Município & Estado & População & $\begin{array}{l}\text { Ideb- } \\
2019\end{array}$ & Posição & Município & Estado & População & \begin{tabular}{|l} 
Ideb- \\
2019
\end{tabular} \\
\hline 1 & Mucambo & $\mathrm{CE}$ & 14.537 & 9,4 & 1 & \begin{tabular}{|l} 
Pires \\
Ferreira
\end{tabular} & $\mathrm{CE}$ & 10.216 & 7,8 \\
\hline 2 & Independência & $\mathrm{CE}$ & 26.178 & 9,1 & 2 & $\begin{array}{l}\text { Novo } \\
\text { Oriente }\end{array}$ & $\mathrm{CE}$ & 27.461 & 7,7 \\
\hline 3 & Coruripe & $\mathrm{AL}$ & \begin{tabular}{|l|}
56.933 \\
\end{tabular} & 8,9 & 3 & Coruripe & $\mathrm{AL}$ & 56.933 & 7,2 \\
\hline 4 & Janiópolis & PR & 6.536 & 8,8 & - & $\begin{array}{l}\text { Jequié da } \\
\text { Praia }\end{array}$ & $\mathrm{AL}$ & 11.887 & 7,2 \\
\hline 5 & Milhã & $\mathrm{CE}$ & \begin{tabular}{|l|}
13.078 \\
\end{tabular} & 8,7 & 5 & $\begin{array}{l}\text { Jijoca de } \\
\text { Jericoacoara }\end{array}$ & $\mathrm{CE}$ & 19.587 & 7,0 \\
\hline 6 & Martinópole & $\mathrm{CE}$ & 10.220 & 8,6 & - & Mucambo & $\mathrm{CE}$ & 14.537 & 7,0 \\
\hline 7 & Pireis Ferreira & $\mathrm{CE}$ & 10.216 & 8,5 & 7 & Ararendá & $\mathrm{CE}$ & 10.500 & 6,9 \\
\hline- & $\begin{array}{l}\text { Serranópolis } \\
\text { do Iguaçu }\end{array}$ & PR & 4.513 & 8,5 & - & Catunda & $\mathrm{CE}$ & 10.342 & 6,9 \\
\hline
\end{tabular}

${ }^{3}$ Disponível em: https://pt.wikipedia.org/wiki/Lista_de_munic\%C3\%ADpios_do_Brasil_por_IDEB. Acesso em: 10 set. 2020. 


\begin{tabular}{|l||l||l||l||l||l|l|l|l|l||}
\hline 9 & Iporã do Oeste & SC & 8.930 & 8,4 & - & Cruz & CE & 22.686 & 6,9 \\
\hline- & Picada Café & RS & 5.564 & 8,4 & - & Sobral & CE & 210.711 & 6,9 \\
\hline- & Sobral & CE & 210.711 & 8,4 & & & & & \\
\hline- & $\begin{array}{l}\text { Teotônio } \\
\text { Vilela }\end{array}$ & AL & 44.667 & 8,4 & & & & & \\
\hline
\end{tabular}

Fonte: Wikipédia ${ }^{4}$

E o Ceará detinha 8 dos 10 primeiros lugares para o $9^{\circ}$ ano do EF, sendo que Alagoas os outros dois, ambos estados nordestinos. No $5^{\circ}$ ano, nos 12 municípios mostrados, metade é cearense, inclusive os dois primeiros lugares (Mucambo, com Ideb de 9,4; Independência, com Ideb de 9,1). Este pioneirismo cearense hoje achou alguns rivais, como veremos nesta análise, em especial Espírito Santo e Goiás, mas com o mesmo recado: educação se gere melhor na base. A tese bastante comum de que seria mais efetivo federalizar a educação básica, porque muitos municípios não teriam condição mínima de dar conta, tem razão de ser, porque, de fato há muitos municípios que são apenas ficção politiqueira, mas não pode ser vista linearmente, tendo em vista que no topo há municípios de regiões pouco desenvolvidas, mas extremamente inovadores. A comparação dos municípios sempre comete incongruências, porque reflete condições sócio-históricas e econômicas muito diversas, como é comparar o município de São Paulo (capital do estado mais importante do país) com algum município do interior do Amazonas. Tamanho, porém, pode não ser documento e não deveria obscurecer o fato de que, num município do interior bem gerido podem-se ter resultados educacionais relevantes, mesmo que a regra de longe mais comum é o desempenho muito insuficiente, de cunho instrucionista (DEMO, 2020).

Na Quadro 2 aparece a série histórica de 2005 a 2019 de alguns municípios com Ideb elevado, onde vemos alguns padrões de desempenho, entre eles: i) o desempenho do $9^{\circ}$ ano é sempre inferior ao do $5^{\circ}$ ano (o que indica diferença notável entre atuação do pedagogo e do licenciado); em Sobral, a diferença para 2019 foi de 1.5 pp.; em Mucambo, de 2.4 pp.; em Independência, de 3,2 pp.; ii) se Sobral servir de exemplo, nota-se dificuldade em manter-se no topo, tanto no $5^{\circ}$, quanto no $9^{\circ}$ ano do EF; iii) ocorrendo tais resultados em regiões menos avançadas (os melhores municípios para o $9^{\circ}$ ano do EF foram todos nordestinos, 8 cearenses, 2 alagoanos), fica a impressão de que o desafio é mais de política educacional, do que de condições externas adversas; iv) parece ser possível, a princípio, ocasionar tal desempenho em qualquer estado ou município, mesmo que não seja questão de princípio, mas de

${ }^{4}$ Disponível em: https://pt.wikipedia.org/wiki/Lista_de_munic\%C3\%ADpios_do_Brasil_por_IDEB. Acesso em: 10 set. 2020. 
viabilização concreta, dependendo bastante da política educacional implantada, até mais do que da infraestrutura disponível; v) embora se reconheça a precariedade da formação original docente (aparece, por exemplo, logo na atuação bem diversa entre pedagogo e licenciado) (DEMO, 2017a), o fato de poder haver desempenho elevado em situações de precário desenvolvimento socioeconômico poderia indicar que é possível lidar com a precariedade da formação docente no local ou em serviço, com resultados surpreendentes.

Quadro 2 - Sobral (CE) - Ideb 2005 - 2019 - Rede municipal

\begin{tabular}{|c|c|c|c|c|c|c|c|c|c|c|}
\hline & & 2005 & 2007 & 2009 & 2011 & 2013 & 2015 & 2017 & 2019 & $\begin{array}{l}\text { Meta } \\
2019\end{array}$ \\
\hline \multirow{2}{*}{$\begin{array}{l}\text { Sobral } \\
\text { (CE) }\end{array}$} & $\overline{5^{\circ} \mathrm{EF}}$ & 4,0 & $4 \overline{4,9}$ & 6 & 7,3 & 7,8 & 8,8 & 9,1 & 8,4 & 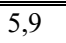 \\
\hline & $9^{\circ} \mathrm{EF}$ & - & - & - & - & 5,8 & 6,7 & 7,2 & 6,9 & 6,4 \\
\hline \multirow{2}{*}{$\begin{array}{l}\text { Mucambo } \\
\text { (CE) }\end{array}$} & $5^{\circ} \mathrm{EF}$ & 3,5 & 4,5 & 4,9 & 7,5 & 6,2 & 6,1 & 6,8 & 9,4 & 5,4 \\
\hline & $9^{\circ} \mathrm{EF}$ & 3,3 & 3,6 & 4,3 & 5,0 & 4,4 & 4,9 & 5,2 & 7,0 & 5,1 \\
\hline \multirow{2}{*}{$\begin{array}{l}\text { Indepen- } \\
\text { cia (CE) }\end{array}$} & $5^{\circ} \mathrm{EF}$ & 2,9 & 3,7 & 4,7 & 6,4 & 6,2 & 7,8 & 6,9 & 9,1 & 4,9 \\
\hline & $9^{\circ} \mathrm{EF}$ & - & 3,2 & 3,7 & 4,3 & 4,5 & 5,2 & 5,5 & 5,9 & 4,7 \\
\hline \multirow{2}{*}{$\begin{array}{l}\text { Coruripe } \\
\text { (AL) }\end{array}$} & 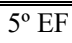 & 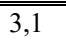 & "4,1 & $4 \overline{4,5}$ & 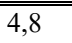 & 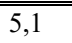 & $\bar{~} 6,5$ & "8,5 & 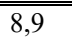 & 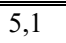 \\
\hline & $9^{\circ} \mathrm{EF}$ & 2,7 & 3,1 & 3,8 & 3,3 & 3,8 & 4,4 & 6,3 & 7,2 & 4,5 \\
\hline \multirow{2}{*}{$\begin{array}{l}\text { Janiópolis } \\
\text { (PR) }\end{array}$} & $\overline{5^{\circ} \mathrm{EF}}$ & 4,1 & 4,2 & $\overline{5,3}$ & $\overline{5,4}$ & 5,5 & 5,5 & 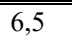 & 8,8 & 6,0 \\
\hline & $9^{\circ} \mathrm{EF}$ & - & - & - & - & - & - & - & - & - \\
\hline \multirow{2}{*}{$\begin{array}{ll}\text { Iporã do } \\
\text { Oeste } \\
\text { (SC) }\end{array}$} & $5^{\circ} \mathrm{EF}$ & 4,7 & 6,5 & 5,7 & 7,4 & 7,2 & 8,0 & 7,9 & 8,4 & 6,5 \\
\hline & $9^{\circ} \mathrm{EF}$ & 4,7 & 5,4 & 5,5 & 5,9 & 5,7 & 6,5 & 6,4 & 6,3 & 6,3 \\
\hline \multirow{2}{*}{$\begin{array}{l}\text { Picada } \\
\text { Café (RS) }\end{array}$} & $5^{\circ} \mathrm{EF}$ & - & 5,2 & 5,7 & 7,0 & 6,3 & 7,9 & 8,0 & 8,4 & 6,6 \\
\hline & $9^{\circ} \mathrm{EF}$ & - & 5,0 & 4,1 & - & 6,9 & - & 6,4 & 6,6 & 6,3 \\
\hline
\end{tabular}

Fonte: INEP

Não faz sentido minimizar questões infraestruturais, apelando para voluntarismos ocasionais, porque estes não duram, enquanto aquelas perduram, mas, o exemplo da política federal de educação, facilmente vista como distante, interventora, lerda, míope, volúvel, indicaria falta clamorosa de política educacional minimamente efetiva, mas que poderia ocorrer em municípios mais facilmente gerenciáveis. Alerte-se, contudo, que os dados podem encobrir laivos instrucionistas marcantes, como é o caso na atual discussão em torno do PISA, em especial após países asiáticos (sobretudo China) ocuparem os primeiros lugares globais, deixando a Europa para trás. Enquanto próceres da metodologia do PISA proclamam os resultados (SCHLEICHER, 2919), os críticos reclamam do instrucionismo repressivo, deformador, autoritário, doentio (RIPLEY, 2013; SAHLBERG, 2017), como é o caso de Zhao (chinês de origem, professor famoso de educação, nos Estados Unidos atualmente) (2014, 
2018), sem falar que os dois países atuais na ponta - China e Singapura - mantêm regimes ditatoriais. Embora o PISA se preocupe com o bem-estar dos estudantes (aplica questionários sobre o tema em toda coleta de dados), sistemas de ensino asiáticos (no caso, mormente o chinês e o singapuriano) não acentuam este compromisso; o suicídio estudantil se elevou, sobretudo com a pressão sobre desempenho em matemática (ZHAO, 2018), além de impactar muito negativamente a criatividade e iniciativa estudantil. Os resultados podem ser obtidos menos pela via pedagógica do que pela via da pressão disciplinar. Há, entre nós, escolas que "treinam" obsessivamente para o Ideb, centram todos os esforços escolares em língua portuguesa e matemática, voltam as atenções dos estudantes para as duas disciplinas, como se fossem as únicas que valem a pena, deixando as outras na penumbra. Como questiona Zhao (2018), confundir aprendizagem com memorização de conteúdo, ou com macetes para catar resposta certa, ou com procedimentos disciplinares forçados, pode ter efeito desastroso na formação estudantil, como a docilização dos corpos e mentes (FOUCAULT, 1977), ao lado de coibir o lado formativo autoral, fundamental para a qualidade de vida, sendo que quase nada fica de importante para a vida ulterior, além da escola (DEMO, 2020a).

Os dados que manejo aqui contêm indicações preliminares em favor da hipótese de que educação se faz melhor na base, no município, na escola, visão que tem muita tradição (por exemplo, americana - até hoje educação é conduzida por conselhos locais; ou o uso no welfare state de deixar educação para os níveis estaduais e municipais), embora talvez se possa falar de certo tom centralizador, vindo do nível federal, que inverte a relevância dos fluxos: ao invés de virem debaixo, da base, são manipulados de cima. Programas americanos fortes como A Nation at Risk (Reagan) ou No Child Left Behind (W. Bush), tipicamente salvacionistas e autocráticos, comprometem a postura mais clássica de que educação básica se resolve na base. Programas nacionais propostos pelo MEC podem abrigar este laivo centralizador, em especial quando são vinculados a repasses de recursos, cujo acesso é condicionado pela adesão às políticas. Fica sempre a pergunta se, ao invés de impor políticas via financiamentos impositivos, não seria mais produtivo investir na capacidade local de se autoconduzir. 


\section{Luzes que vêm debaixo}

Quando os resultados do Ideb são focados nas escolas municipais (Quadro 3), por faixa de resultados, fica a sugestão de que a capacidade municipal pode estar muito além do que se imagina: enquanto há, de fato, escolas que não reagem, outras podem reagir de maneira bastante positiva e mesmo surpreendente, dependendo, em parte, de sua iniciativa e concerto de esforços locais. Na média nacional (Brasil), havia 6,9\% de escolas com Ideb de até 3,7; $24,2 \%$ de 3,8 a 4,9;31,1\% de 5,0 a 5,9; e 37,8\% acima de 6,0. Este perfil já contém uma mensagem interessante: enquanto na menor faixa havia 6,9\% das escolas, na maior, eram $37,8 \%$, uma cifra quase 6 vezes maior. Sendo o país muito desequilibrado regionalmente, a média é opaca, o que demanda observar as regiões e seus estados. No Norte, havia $21,4 \%$ de escolas com Ideb até 3,$7 ; 40,8 \%$ com 3,8 a 4,9; 26,5\% com 5,0 a 5,9; e 11,3\% acima de 6,0. É um perfil de uma região afetada por muitos problemas socioeconômicos, além de suas distâncias geográficas e outras dificuldades de acesso, mas, mesmo aí, alguns estados oferecem cifras animadoras, com destaque para o Acre: $35,5 \%$ das escolas tinham Ideb acima de 6,0 (perto da média nacional de 37,8\%). Há também o outro lado da moeda: Pará, o estado mais socioculturalmente destacado na região, tinha apenas 5,4\% de escolas com Ideb acima de 6,0. Amapá, com 116 escolas mapeadas pelo Ideb 2019, apenas 1 tinha desempenho acima de 6,0. A mensagem possível do Acre é que políticas educacionais locais mais bem montadas, cuidadas, geridas, comprometidas, podem ter resultados favoráveis.

Quadro 3 - Ideb Anos Iniciais EF - Rede Municipal - Escolas municipais e Ideb 2019 (faixas do Ideb).

\begin{tabular}{|c|c|c|c|c|c|c|c|c|c|}
\hline \multirow{2}{*}{$\begin{array}{l}\text { Reg./Esta- } \\
\text { dos }\end{array}$} & \multirow{2}{*}{$\begin{array}{l}\text { Escol. } \\
\text { com Ideb } \\
2019\end{array}$} & \multicolumn{8}{|c|}{ Faixas de Ideb } \\
\hline & & Até 3,7 & $\%$ & $\begin{array}{l}\text { De } 3,8 \text { a } \\
4,9\end{array}$ & $\%$ & $\begin{array}{l}\text { De } 5,0 \text { a } \\
5,9\end{array}$ & $\%$ & $\begin{array}{l}6,0 \text { ou } \\
\text { mais }\end{array}$ & $\%$ \\
\hline Brasil & 35.071 & 2.433 & 6,9 & 8.472 & 24,2 & 10.918 & 31,1 & 13.248 & 37,8 \\
\hline Norte & 3.737 & 801 & 21,4 & 1.523 & 40,8 & 989 & 26,5 & 424 & 11,3 \\
\hline Rondônia & 328 & 6 & 1,8 & 104 & 31,7 & 137 & 50,9 & 51 & 15,5 \\
\hline Acre & 121 & 8 & 6,6 & 29 & 24,0 & 41 & 33,9 & 43 & 35,5 \\
\hline Amazonas & 669 & 149 & 22,3 & 213 & 31,8 & 177 & 26,5 & 130 & 19,4 \\
\hline Roraima & 76 & 6 & 7,9 & 36 & 47,4 & 17 & 22,4 & 17 & 22,4 \\
\hline Pará & 2.080 & 596 & 28,7 & 934 & 44,9 & 437 & 21,0 & 113 & 5,4 \\
\hline Amapá & 116 & 18 & 15,5 & 67 & 57,8 & 30 & 25,9 & 1 & 0,9 \\
\hline Tocantins & 347 & 18 & 5,2 & 140 & 40,3 & 120 & 34,6 & 69 & 19,9 \\
\hline Nordeste & 14.089 & 1.570 & 111,1 & 5.455 & 38,7 & 4.350 & 30,9 & 2.714 & 19,3 \\
\hline Maranhão & 2.250 & 412 & 18,3 & 1.186 & 52,7 & 511 & 22,7 & 141 & 6,3 \\
\hline Piauí & 1.035 & 122 & 11,8 & 413 & 39,9 & 248 & 24,0 & 252 & 24,3 \\
\hline Ceará & 2.347 & 6 & 0,3 & 162 & 6,9 & 786 & 33,5 & 1.393 & 59,4 \\
\hline
\end{tabular}




\begin{tabular}{|c|c|c|c|c|c|c|c|c|c|}
\hline Rio Gr. Norte & 648 & 129 & 19,9 & 329 & 50,8 & 156 & 24,1 & 34 & 5,2 \\
\hline Paraíba & 954 & 100 & 10,5 & 393 & 41,2 & 342 & 35,8 & 119 & 12,5 \\
\hline Pernambuco & 1.912 & 70 & 3,7 & 750 & 39,2 & 811 & 42,4 & 281 & 14,7 \\
\hline Alagoas & 846 & 30 & 3,5 & 327 & 3897 & 335 & 39,6 & 154 & 18,2 \\
\hline Sergipe & 496 & 133 & 26,8 & 263 & 53,0 & 82 & 16,5 & 18 & 3,6 \\
\hline Bahia & 3.601 & 568 & 15,8 & 1.632 & 45,3 & 1.079 & 30,0 & 322 & 8,9 \\
\hline Sudeste & 10.154 & 36 & 0,4 & 899 & 8,9 & 3.261 & 32,1 & 5.958 & 58,7 \\
\hline Minas Gerais & 2.839 & 3 & 0,1 & 164 & 5,8 & 982 & 34,6 & 1.690 & 59,6 \\
\hline Espírito Santo & 691 & 1 & 0,1 & 56 & 8,1 & 311 & 45,0 & 323 & 76,7 \\
\hline Rio de Janeiro & 2.289 & 32 & 1,4 & 633 & 27,7 & 1.057 & 46,2 & 567 & 24,8 \\
\hline S. Paulo & 4.335 & 0 & 0,0 & 46 & 1,1 & 911 & 21,0 & 3.378 & 77,9 \\
\hline$\overline{\mathrm{Sul}}$ & 5.128 & 3 & ,01 & 323 & 6,3 & 1.432 & 27,9 & 3.370 & 65,7 \\
\hline Paraná & 2.422 & 0 & 0,0 & 87 & 3,6 & 554 & 22,9 & 1.781 & 73,5 \\
\hline Santa Catarina & 1.191 & 1 & 0,1 & 34 & 2,9 & 308 & 25,9 & 848 & 71,2 \\
\hline Rio Gr. Sul & 1.515 & 2 & 0,1 & 202 & 13,3 & 570 & 37,6 & 741 & 48,9 \\
\hline Centro-Oeste & 1.963 & 23 & 1,2 & 272 & 13,9 & 886 & 45,1 & 782 & 39,8 \\
\hline Mato Gr. Sul & 387 & 16 & 4,1 & 99 & 25,6 & 180 & 46,5 & 92 & 23,8 \\
\hline Mato Grosso & 448 & 5 & 1,1 & 69 & 15,4 & 241 & 53,8 & 133 & 29,7 \\
\hline Goiás & 1.128 & 2 & 0,3 & 104 & 9,2 & 465 & 41,2 & 557 & 49,4 \\
\hline Distrito Federal & - & - & - & - & - & - & - & - & - \\
\hline
\end{tabular}

Fonte: INEP

No Nordeste, havia $11,1 \%$ de escolas com Ideb de até 3,7; 38,7\% de 3,8 a 4,9; 30,9\% de 5,0 a 5,9; e 19,3\% com mais de 6,0. Está alguns furos acima do Norte, mas é sabidamente uma região com muitas dificuldades socioeconômicas. No entanto, o Ceará tinha 59,4\% de suas escolas municipais com Ideb acima de 6,0, mesmo sendo um brilho relativamente solitário (a próxima cifra era do Piauí, com 24,3\%). Alguns estados tinham cifra melhor, como São Paulo (77,9\%, a melhor do Quadro), mas não há como comparar a condição socioeconômica dos dois estados. Espírito Santo vinha logo atrás, com 76,7\%; depois, Paraná, com 73,5\% e Santa Catarina, com 71,2\%. Naturalmente, existe o outro lado: alguns estados nordestinos não parecem reagir: Maranhão tinha 6,3\% de escolas com Ideb acima de 6,0; Rio Grande de Norte, com 5,2\%; Sergipe, com 3,6; Bahia, com 8,9\%.

No Sudeste e Sul também há exemplos menos edificantes: Rio de Janeiro tinha apenas 24,8\% de escolas municipais com Ideb acima de 6,0; Rio Grande do Sul, com 48,9\%, não chegava à metade. E no Centro-Oeste, Goiás tinha a melhor cifra relativa: 49,4\%.

Focando agora, não as escolas municipais, mas os municípios (Quadro 4), o perfil se confirma, com alguns matizes a mais. Na média nacional (Brasil), havia apenas 2,1\% de municípios com Ideb de até 3,$7 ; 23,8 \%$ de 3,8 a 4,9; $29,7 \%$ de 5,0 a 50,9; 44,4\% de 6,0 ou mais. É um perfil ainda mais alvissareiro que o anterior das escolas municipais. Enquanto as escolas são um pouco menos sensíveis aos desequilíbrios regionais, os municípios os refletem 
mais claramente. No Norte, apenas 4,9\% dos municípios tinham Ideb acima de 6,0. Sendo que Acre tinha só $14,3 \%$, mesmo sendo a melhor cifra regional (Rondônia tinha cifra similar, de 14\%). Os outros estados praticamente não tinham municípios nessa faixa (Tocantins chegou a 6,9\%). No Nordeste, 14\% dos municípios tinham Ideb acima de 6,0, mas o Ceará despontava com $71,2 \%$, brilhando quase sozinho. Era em muito ultrapassado por São Paulo, com 91,3\%; mas rivalizava bem com Paraná e Santa Catarina (77,8\%, e 74,8\%, respectivamente). Naturalmente, chama ainda mais a atenção que a grande maioria dos municípios tinham cifras muito baixas: Sergipe, com nenhum município.

Quadro 4 - Ideb Anos Iniciais EF - Rede Municipal - Municípios com Ideb calculado para 2019 e resultado para 2019 por faixas do Ideb.

\begin{tabular}{|c|c|c|c|c|c|c|c|c|c|}
\hline \multirow{2}{*}{$\begin{array}{l}\text { Reg./Esta- } \\
\text { dos }\end{array}$} & \multirow{2}{*}{$\begin{array}{l}\text { Mun. } \\
\text { com } \\
\text { Ideb } \\
2019\end{array}$} & \multicolumn{8}{|c|}{ Faixas de Ideb } \\
\hline & & Até 3,7 & $\%$ & $\begin{array}{l}\text { De } 3,8 \text { a } \\
4,9\end{array}$ & $\%$ & $\begin{array}{l}\text { De } 5,0 \text { a } \\
5,9\end{array}$ & $\%$ & $\begin{array}{ll}6,0 \text { ou } \\
\text { mais }\end{array}$ & $\%$ \\
\hline Brasil & 5.139 & 107 & 2,1 & 1.221 & 23,8 & 1.527 & 29,7 & 2.287 & $\overline{444,4}$ \\
\hline Norte & 425 & 37 & 8,7 & 234 & $\overline{55,1}$ & 133 & 31,3 & 21 & 4,9 \\
\hline Rondônia & 50 & 0 & 0,0 & 12 & 24,0 & 31 & 62,0 & 7 & 14,0 \\
\hline Acre & 21 & 1 & 4,8 & 7 & 33,3 & 10 & 47,6 & 3 & 14,3 \\
\hline Amazonas & 59 & 13 & 22,0 & 37 & 62,7 & 9 & 15,3 & 0 & 0,0 \\
\hline Roraima & 9 & 0 & 0,0 & 8 & 88,9 & 1 & 11,1 & 0 & 0,0 \\
\hline Pará & 141 & 17 & 12,1 & 97 & 63,8 & 25 & 17,7 & 2 & 1,4 \\
\hline Amapá & 15 & 2 & 13,3 & 12 & 80,0 & 1 & 6,7 & 0 & 0,0 \\
\hline Tocantins & 130 & 4 & 3,1 & 61 & 46,9 & 56 & 43,1 & 9 & 6,9 \\
\hline Nordeste & 1.741 & 70 & 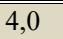 & 869 & 49,9 & 559 & 32,1 & 243 & $\overline{14,0}$ \\
\hline Maranhão & 212 & 2 & 0,9 & 156 & 73,6 & 51 & 24,1 & 3 & 1,4 \\
\hline Piauí & 217 & 13 & 6,0 & 100 & 46,1 & 75 & 34,6 & 29 & 13,4 \\
\hline Ceará & 184 & 0 & 0,0 & 3 & 1,6 & 50 & 27,2 & 131 & 71,2 \\
\hline Rio Gr. Norte & 149 & 22 & 14,8 & 89 & 59,7 & 33 & 22,1 & 5 & 3,4 \\
\hline Paraíba & 211 & 6 & 2,8 & 108 & 51,2 & 75 & 35,3 & 22 & 10,4 \\
\hline Pernambuco & 183 & 0 & 0,0 & 72 & 39,3 & 92 & 50,3 & 19 & 10,4 \\
\hline Alagoas & 101 & 0 & 0,0 & 40 & 39,6 & 52 & 51,5 & 9 & 8,9 \\
\hline Sergipe & 73 & 17 & 23,3 & 50 & 68,5 & 6 & 8,2 & 0 & 0,0 \\
\hline Bahia & 411 & 10 & 2,4 & 251 & 61,1 & 125 & 30,4 & 25 & 6,1 \\
\hline Sudeste & 1.549 & 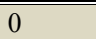 & 0,0 & 40 & 2,6 & 365 & 23,6 & 1.144 & $\overline{773,9}$ \\
\hline Mias. Gerais & 776 & 0 & 0,0 & 21 & 2,7 & 229 & 29,5 & 526 & 67,8 \\
\hline Esp. Santo & 74 & 0 & 0,0 & 2 & 2,7 & 29 & 39,2 & 43 & 58,1 \\
\hline Rio de Janeiro & 90 & 0 & 0,0 & 16 & 17,8 & 55 & 61,1 & 19 & 21,1 \\
\hline S. Paulo & 609 & 0 & 0,0 & 1 & 0,2 & 52 & 8,5 & 556 & 91,3 \\
\hline Sul & 995 & 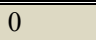 & 0,0 & 33 & 3,3 & 276 & 27,7 & "686 & $\overline{688,9}$ \\
\hline Paraná & 397 & 0 & 0,0 & 1 & 0,3 & 87 & 21,9 & 309 & 77,8 \\
\hline Santa Catarina & 262 & 0 & 0,0 & 1 & 0,4 & 65 & 24,8 & 196 & 74,8 \\
\hline Rio Gr. Sul & 336 & 0 & 0,0 & 31 & 9,2 & 124 & 36,9 & 181 & 53,9 \\
\hline Centro-Oeste & 429 & 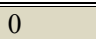 & 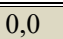 & 45 & 10,5 & 194 & 445,2 & 190 & 444,3 \\
\hline
\end{tabular}




\begin{tabular}{||l|l|l|l|l|l|l|l|l|l||}
\hline Mato Gr. Sul & 73 & 0 & 0,0 & 21 & 28,8 & 41 & 56,2 & 11 & 15,1 \\
\hline Mato Grosso & 119 & 0 & 0,0 & 13 & 10,9 & 67 & 56,3 & 39 & 32,8 \\
\hline Goiás & 237 & 0 & 0,0 & 11 & 4,6 & 86 & 36,3 & 140 & 59,1 \\
\hline Distrito Federal & - & - & - & - & - & - & - & - & - \\
\hline
\end{tabular}

Fonte: INEP

De novo, Rio de Janeiro tinha apenas $21,1 \%$ de municípios com Ideb acima de 6,0; Rio Grande do Sul, 53,9\%. E no Centro-Oeste, Goiás aparecia com 59,1\%, indicando, como o Espírito Santo $(58,1 \%)$, ter condição de avançar. Muitos estados não possuem mais municípios com Ideb até 3,7, como nas regiões Sudeste, Sul e Centro-Oeste. Reconheçamos que a heterogeneidade de desempenho marca o cenário, sobretudo no Nordeste, mas, mesmo assim, os dados insinuam que é possível divisar políticas educacionais municipais bem mais efetivas. O caso do Rio de Janeiro poderia ser emblemático, onde apenas $21,1 \%$ dos municípios tiveram Ideb acima de 6,0, enquanto São Paulo teve 91,3\%. Insinua-se que políticas educacionais no Rio são extremamente menos efetivas que as de São Paulo, tendo parte nisso, com certeza, o atraso socioeconômico do Rio, mas igualmente a desarrumação atávica do estado em termos de políticas públicas. Não é o caso retirar conclusões afoitas, porquanto São Paulo não faz mais que sua obrigação constitucional. Mas desempenhos como do Ceará, Espírito Santo, Goiás indicariam que políticas educacionais locais mais condizentes, consistentes e sustentadas, podem ser um grande diferencial. E isto depende da capacidade municipal de se autoconduzir.

\section{Um olhar mais complexo}

Os dados do capítulo anterior são dos Anos Iniciais. Agora vamos observar os Anos Finais, dentro do mesmo ângulo de análise. Como notamos acima, mesmo nos municípios do topo do Ideb, há diferença marcante entre os resultados dos Anos Iniciais e dos Anos Finais. Esta queda é significativa e de explicação complexa, sugerindo uma diferença acentuada entre a atuação do pedagogo e do licenciado. Parte da complicação está em ver pedagogia como curso menos exigente que a licenciatura, esperando-se deste melhor desempenho. Na escola é ao contrário, ostensivamente. Um estudo recente do BID (2018) sobre a profissão professor ilustra algumas facetas deste imbróglio, começando pela constatação de que, analisando as matrículas das universidades, há cerca de $20 \%$ em cursos de educação, embora, quando se pergunta ao estudante do PISA (com 15 anos de idade) se gostaria de ser professor, apenas $5 \%$ confirmam. O BID usa o termo pejorativo de "refúgio" para cursos de educação, por 
serem uma modalidade visivelmente facilitada - busca-se um diploma fácil. Embora licenciatura bravateie ser curso melhor que pedagogia e, formalmente, talvez pudesse até ser, na prática o desempenho do pedagogo é muito superior. O licenciado, por sua vez, reclama do desempenho do pedagogo, quando o aluno chega ao $6^{\circ}$ ano e é visto como despreparado para os Anos Finais, sobretudo em matemática. A matemática do pedagogo é considerada insuficiente, ou mesmo amadora.

A possível vantagem do pedagogo é que, oferecendo todas as matérias, pode criar com o estudante uma interlocução e relacionamento de relativa confiança e cuidado, algo que agora é exigido na BNCC (DEMO, 2019), sob a rubrica da formação socioemocional. A pedagogia parece ter proximidade maior com este desafio, enquanto a licenciatura, por ser, muitas vezes, um curso apenas tingido de pedagogia, pode ser refratária a "cuidar do aluno". Como regra, o licenciado entra em sala, dá aula e se vai. Instado a ter de cuidar do aluno, pode estranhar, porque lhe parece algo fora de sua alçada técnica. No entanto, é papel pedagógico de todo professor procurar garantir ao estudante o direito de aprender. Esta discussão, para não se tornar bizantina e pouco útil, precisa focar as questões que interessam sem melindres, em especial a necessidade de reconstruir os cursos na universidade (pedagogia e licenciatura), voltados, não mais para um especialista do ensino, mas da aprendizagem (DEMO, 2018). A própria BNCC declara, talvez num ato falho, a imperiosidade de "recriar a escola", porque reconhece que a escola vigente não está à altura dos estudantes.

Em termos locais, municipais, a questão mais candente é a formação permanente dos docentes, para que, superando o cacoete instrucionista (apenas repassar conteúdo), encarem o compromisso de garantir, da melhor maneira possível, que os estudantes aprendam efetivamente, como autores (DEMO, 2015). Os pedagogos têm o desafio, nem sempre bem exarado, de "alfabetizar" em até três anos (na média nacional, após três anos, sequer metade se alfabetiza) (BRASILEIRO DA EDUCAÇÃO BÁSICA, 2019). Os Licenciados, de superar o instrucionismo do mero repasse de conteúdos curriculares, tirando sempre a limpo se os estudantes avançam como autores. Isto leva a mudar por completo os usos e costumes das jornadas pedagógicas ou algo parecido, porque não acrescentam em geral nada de útil para a aprendizagem dos estudantes, sendo que grande parte se esvai em teatros motivacionalistas inconsequentes. Os professores precisam estudar, ler, pesquisar, elaborar, argumentar, se autorrenovar permanentemente, durante o trabalho, porque é parte constitutiva de seu trabalho. A deficiência da licenciatura pode estar no desempenho mais baixo dos Anos Finais, ainda que não seja, nunca, o caso achar culpados. Mesmo que o professor não se desempenhe de modo suficiente, é referência insubstituível para mudar a escola, já que, mudar a escola é 
mudar o professor. Qualquer questionamento da formação original dos docentes só pode ter o sentido de contrapropor alternativas que valorizem os profissionais da aprendizagem, em todos os sentidos.

O Quadro 5 mostra dados para escolas dos Anos Finais e faixas do desempenho no Ideb, cabendo logo constatar que as cifras são bastante mais baixas do que as dos Anos Iniciais (Quadro 3): apenas 14,6\% das escolas municipais tinham Ideb acima de 5,5 (no outro quadro a cifra foi de $37,8 \%$ ). No Norte, eram apenas 3,2\%, aparecendo a melhor cifra em Tocantins, com 19,3\%; depois vinha Rondônia, com 8\%. Já Acre, destaque nos Anos Iniciais, sumia nos Anos Finais: nenhuma escola estava na faixa mais alta. Pode surpreender que o bom desempenho nos Anos Iniciais não acompanhe o dos Anos Finais: a queda é esperada, porque é padrão nacional; mas a queda no Acre foi absoluta! Significa, quiçá, que o estado lida melhor com os pedagogos, não tendo ainda achado a maneira de arrumar o licenciado. No Nordeste, $10,5 \%$ das escolas municipais tinham Ideb acima de 5,5, e Ceará era o maior destaque, mas com 41,4\% também ocorria em praticamente a metade da cifra dos Anos Iniciais.

Quadro 5 - IDEB Anos Finais EF - Rede Municipal - Escolas com IDEB marcado para 2019 e IDEB 2019

\begin{tabular}{|c|c|c|c|c|c|c|c|c|c|}
\hline \multirow{2}{*}{$\begin{array}{l}\text { Reg./Esta- } \\
\text { dos }\end{array}$} & \multirow{2}{*}{$\begin{array}{l}\text { Munic. } \\
\text { com } \\
\text { IDEB } \\
2019\end{array}$} & \multicolumn{8}{|c|}{ Faixas de Ideb } \\
\hline & & Até 3,4 & $\%$ & $\begin{array}{l}\text { De 3,5 a } \\
4,4\end{array}$ & $\%$ & $\begin{array}{ll}\text { De } 4,5 \text { a } \\
5,4\end{array}$ & $\%$ & $\begin{array}{ll}5,5 \quad \text { ou } \\
\text { mais }\end{array}$ & $\%$ \\
\hline Brasil & 16.279 & 2.388 & 13,7 & 5.558 & 34,1 & 5.959 & 36,6 & 2.374 & 14,6 \\
\hline Norte & 1.752 & 543 & 31,0 & 768 & 43,8 & 385 & 22,0 & 56 & 3,2 \\
\hline Rondônia & 87 & 6 & 6,9 & 35 & 40,2 & 39 & 44,8 & 7 & 8,0 \\
\hline Acre & 23 & 6 & 26,1 & 16 & 56,5 & 4 & 47,4 & 0 & 0,0 \\
\hline Amazonas & 349 & 99 & 28,4 & 143 & 41,0 & 95 & 27,2 & 12 & 3,4 \\
\hline Roraima & 6 & 2 & 33,3 & 3 & 50,0 & 1 & 16,7 & 0 & 0,0 \\
\hline Pará & 1.173 & 407 & 34,7 & 532 & 45,4 & 218 & 18,6 & 16 & 1,4 \\
\hline Amapá & 5 & 2 & 40,0 & 3 & 60,0 & 0 & 0,0 & 0 & 0,0 \\
\hline Tocantins & 109 & 21 & 19,3 & 39 & 35,8 & 28 & 25,7 & 21 & 19,3 \\
\hline Nordeste & 8.641 & 1.668 & 19,3 & 3.429 & 39,7 & 2.639 & 30,5 & 905 & 10,5 \\
\hline Maranhão & 1.676 & 527 & 31,4 & 855 & 51,0 & 269 & 16,1 & 25 & 1,5 \\
\hline Piauí & 683 & 87 & 12,7 & 270 & 39,5 & 223 & 32,7 & 103 & 15,1 \\
\hline Ceará & 1.940 & 18 & 0,9 & 260 & 13,4 & 1.052 & 54,2 & 610 & 31,4 \\
\hline Rio Gr. Norte & 323 & 122 & 37,8 & 153 & 4734 & 43 & 13,3 & 5 & 1,5 \\
\hline Paraíba & 478 & 101 & 21,1 & 235 & 49,2 & 132 & 27,6 & 10 & 2,1 \\
\hline Pernambuco & 935 & 67 & 7,2 & 408 & 43,6 & 376 & 40,2 & 84 & 9,0 \\
\hline Alagoas & 391 & 19 & 4,9 & 192 & 49,1 & 137 & 35,0 & 43 & 11,0 \\
\hline Sergipe & 234 & 96 & 41,0 & 113 & 48,3 & 23 & 9,8 & 2 & 0,9 \\
\hline Bahia & 1.981 & 631 & 31,9 & 943 & 47,6 & 384 & 19,4 & 23 & 1,2 \\
\hline
\end{tabular}




\begin{tabular}{|l|l|l|l|l|l|l|l|l|l|}
\hline Sudeste & 3.768 & 112 & 3,0 & 880 & 23,4 & 1.933 & 51,3 & 843 & 22,4 \\
\hline Minas Gerais & 1.072 & 31 & 2,9 & 325 & 30,3 & 530 & 49,4 & 186 & 17,4 \\
\hline Espírito Santo & 368 & 11 & 3,0 & 112 & 30,4 & 182 & 49,5 & 63 & 17,1 \\
\hline Rio de Janeiro & 939 & 65 & 6,9 & 333 & 3535 & 443 & 47,2 & 98 & 10,4 \\
\hline S. Paulo & 1.389 & 5 & 0,4 & 110 & 7,9 & 778 & 56,0 & 496 & 35,7 \\
\hline \hline Sul & 1.578 & 50 & 3,2 & 328 & 20,8 & 724 & 45,9 & 476 & 30,2 \\
\hline Paraná & 20 & 0 & 0,0 & 1 & 5,0 & 11 & 55,0 & 8 & 40,0 \\
\hline Santa Catarina & 583 & 5 & 0,9 & 61 & 10,5 & 252 & 43,2 & 265 & 45,5 \\
\hline Rio Gr. Sul & 975 & 45 & 4,6 & 266 & 27,3 & 461 & 47,3 & 203 & 20,8 \\
\hline \hline Centro-Oeste & 540 & 15 & 2,8 & 153 & 28,3 & 278 & 51,5 & 94 & 17,4 \\
\hline Mato Gr. Sul & 165 & 7 & 4,2 & 41 & 24,8 & 90 & 54,5 & 27 & 16,4 \\
\hline Mato Grosso & 154 & 3 & 1,9 & 61 & 39,6 & 72 & 46,8 & 18 & 11,7 \\
\hline Goiás & 221 & 5 & 2,3 & 51 & 23,1 & 116 & 52,5 & 49 & 22,2 \\
\hline Distrito Federal & - & - & - & - & - & - & - & - & - \\
\hline
\end{tabular}

Fonte: INEP

O estado que melhor desempenhou foi Santa Catarina, com 45,5\% de escolas municipais com Ideb acima de 5,5; São Paulo ficou com 35,7\%, apenas um pouco acima do Ceará. No Centro-Oeste Goiás se destaca, com 22,2\%. Na outra ponta, Pará tinha ainda 34,7\% de escolas municipais dos Anos Finais com Ideb de até 3,4, superado apenas por Sergipe, com 41,0\% e Amapá, com 40,0\%. Somente o Paraná não tinha mais escolas municipais com Ideb de até 3,4 e Santa Catarina ainda tinha 5\%. Numa comparação entre Pará e Ceará, o primeiro tinha $34,7 \%$ de escolas com Ideb de até 3,4, e o Ceará, 0,9\%; mas este tinha 31,4\% de escolas com Ideb acima de 5,5, enquanto Pará apenas 1,4\%. Esta comparação ilustra os dois lados da moeda: é grande desafio resolver a questão localmente, mas alguns exemplos indicam que é, possivelmente, a melhor ideia.

Focando agora municípios da Rede Pública, nas faixas do Ideb (Quadro 6), observamos que apenas $11.9 \%$ dos municípios tinham Ideb acima de 5,5, concentrando-se $55,6 \%$ na faixa de 3,5 a 4,4. No Norte praticamente inexistiam casos nesta faixa mais alta, voltando a sobressair Acre, com 5,0\%. No Nordeste, somente 5,1\% dos municípios nos Anos Finais da Rede Pública tinham Ideb de 5,5 ou mais, com realce ostensivo do Ceará: 26,6\%. São Paulo tinha a melhor cifra, com 33,4\%, tendo destaque superlativo Goiás, com 27,2\%, acima da cifra do Ceará. Em ambos os casos, não havia mais municípios com Ideb de até 3,4. 
Quadro 6 - Ideb Anos Finais EF - Rede Pública - Municípios com Ideb marcado para 2019 e Ideb 2019

\begin{tabular}{|c|c|c|c|c|c|c|c|c|c|}
\hline \multirow{2}{*}{$\begin{array}{l}\text { Reg./Esta- } \\
\text { dos }\end{array}$} & \multirow{2}{*}{\begin{tabular}{|l} 
Munic. \\
com Ideb \\
2019
\end{tabular}} & \multicolumn{8}{|c|}{ Faixas de Ideb } \\
\hline & & Até 3,4 & $\%$ & $\begin{array}{l}\text { De } 3,5 \text { a } \\
4,4\end{array}$ & $\%$ & $\begin{array}{lll}\text { De } & 4,5 \text { a } \\
5,4 & & \end{array}$ & $\%$ & $\begin{array}{l}5,5 \text { ou } \\
\text { mais }\end{array}$ & $\%$ \\
\hline Brasil & 5.287 & 373 & 7,1 & 1.717 & 32,5 & 2.566 & 48,5 & 631 & 11,9 \\
\hline Norte & 412 & 59 & 14,3 & 229 & 55,6 & 121 & 29,4 & 3 & 0,7 \\
\hline Rondônia & 51 & 0 & 0,0 & 12 & 23,5 & 38 & 74,5 & 1 & 2,0 \\
\hline Acre & 20 & 0 & 0,0 & 6 & 30,0 & 13 & 65,0 & 1 & 5,0 \\
\hline Amazonas & 61 & 8 & 13,1 & 42 & 68,9 & 11 & 18,0 & 0 & 0,0 \\
\hline Roraima & 11 & 2 & 18,2 & 9 & 81,8 & 0 & 0,0 & 0 & 0,0 \\
\hline Pará & 137 & 37 & 27,0 & 86 & 62,8 & 14 & 10,2 & 0 & 0,0 \\
\hline Amapá & 14 & 6 & 42,9 & 8 & 57,1 & 0 & 0,0 & 0 & 0,0 \\
\hline Tocantins & 118 & 6 & 5,1 & 66 & 55,9 & 45 & 38,1 & 1 & 0,8 \\
\hline Nordeste & 1.731 & 296 & 17,1 & 872 & 50,4 & 475 & 27,4 & 88 & 5,1 \\
\hline Maranhão & 210 & 30 & 14,3 & 138 & 65,7 & 42 & 20,0 & 0 & 0,0 \\
\hline Piauí & 218 & 16 & 7,3 & 108 & 49,5 & 81 & 37,2 & 13 & 6,0 \\
\hline Ceará & 184 & 0 & 0,0 & 12 & 6,5 & 123 & 66,8 & 49 & 26,6 \\
\hline Rio Gr. Norte & 157 & 60 & 38,2 & 80 & 51,0 & 16 & 10,2 & 1 & 0,6 \\
\hline Paraíba & 214 & 50 & 23,4 & 124 & 57,9 & 38 & 17,8 & 2 & 0,9 \\
\hline Pernambuco & 182 & 4 & 2,2 & 82 & 45,1 & 84 & 46,2 & 12 & 6,6 \\
\hline Alagoas & 100 & 2 & 2,0 & 55 & 55,0 & 35 & 35,0 & 8 & 8,0 \\
\hline Sergipe & 74 & 27 & 36,5 & 44 & 59,5 & 3 & 4,1 & 0 & 0,0 \\
\hline Bahia & 392 & 107 & 27,3 & 229 & 5834 & 53 & 13,5 & 3 & 0,8 \\
\hline Sudeste & 1.621 & 7 & 0,4 & 342 & 21,1 & 992 & 61,2 & 280 & 17,3 \\
\hline Minas Gerais & 829 & 6 & 0,7 & 270 & 32,6 & 492 & 59,3 & 61 & 7,4 \\
\hline Espírito Santo & 78 & 0 & 0,0 & 10 & 12,8 & 59 & 75,6 & 9 & 11,5 \\
\hline Rio de Janeiro & 91 & 1 & 1,1 & 41 & 45,1 & 47 & 51,6 & 2 & 2,2 \\
\hline S. Paulo & 623 & 0 & 0,0 & 21 & 3,4 & 394 & 63,2 & 208 & 33,4 \\
\hline Sul & 1.055 & 1 & 0,6 & 190 & 17,5 & 701 & 64,4 & 190 & 17,5 \\
\hline Paraná & 389 & 0 & 0,0 & 22 & 5,7 & 286 & 73,5 & 81 & 20,8 \\
\hline Santa Catarina & 271 & 2 & 0,7 & 63 & 23,2 & 173 & 63,8 & 33 & 12,2 \\
\hline Rio Gr. Sul & 428 & 5 & 1,2 & 105 & 24,5 & 242 & 56,5 & 76 & 17,8 \\
\hline Centro-Oeste & 435 & 4 & 0,9 & 84 & 19,3 & 277 & 63,7 & 70 & 16,1 \\
\hline Mato Gr. Sul & 70 & 1 & 104 & 26 & 37,1 & 40 & 57,1 & 3 & 4,3 \\
\hline Mato Grosso & 125 & 3 & 2,4 & 44 & 35,2 & 76 & 60,8 & 2 & 1,6 \\
\hline Goiás & 239 & 0 & 0,0 & 14 & 5,9 & 160 & 66,9 & 65 & 27,2 \\
\hline Distrito Federal & 1 & 0 & 0,0 & 0 & 0,0 & 1 & 100 & 0 & 0,0 \\
\hline
\end{tabular}

Fonte: INEP

O desempenho na faixa mais alta mostra o peso da heterogeneidade de políticas educacionais: enquanto alguns municípios avançam, aparentemente, por conta própria, a grande maioria patina. Deixando de lado São Paulo, os dois estados mais exemplares são Ceará, com 26,6\% de municípios com Ideb de 5,5 ou mais e Goiás, com 27,2\%. No entanto, 
Goiás não tem o mesmo desempenho relativo a escolas, o que sugere ser mais bem sucedido na movimentação municipal como tal.

\section{Aposta municipal/local}

Para ancorar um pouco mais a aposta municipal/local, recorro a dados do Ensino Médio, com o intuito de contrapor gestão estadual com municipal. Assim, o Ideb de 2019 nos três estados mais destacados para este enfoque - Ceará, Espírito Santo e Goiás - foi: 4,5; 4,7; 4,4 , respectivamente. São cifras relativamente interessantes na mediocridade nacional, mas sem maior destaque. Houve três casos com Ideb de 5 ou mais: Santa Catarina, com 5,1 (o maior de todos); e Minas Gerais e Rio Grande do Sul, ambos com 5,0.

Quando, entretanto, se foca a rede estadual do Ensino Médio nos municípios, por faixa de desempenho no Ideb, o maior destaque cabe ao Espírito Santo, com 20\% de municípios com Ideb de 5,2 ou mais; a seguinte cifra maior é de Goiás, com 8,8\%; Ceará aparece apenas com 1,6\%. Parece, então, que Espírito Santo mobiliza melhor seus municípios, seguindo-se Goiás. Seguindo nesta rota, e focando as escolas do Ensino Médio da rede estadual, Espírito Santo tem a melhor cifra na faixa mais alta, de 23,7\%; segue Ceará, com 19,6\%; e Goiás, com $18 \%$.

O argumento seria que, em termos de política estadual, os três estados não se destacam - estão, por assim dizer, na vala comum nacional no Ensino Médio. Mas em termos de reação da escola - até certo ponto à revelia da política estadual - há casos de êxito visível, sobretudo nos três estados citados. Pernambuco está se insinuando, com 15,5\%. São Paulo também, com $15,5 \%$, mas este é um caso à parte.

É parte do argumento que mobilizar energias burocráticas é bem mais difícil do que mobilizar as energias locais, sobretudo dos professores. Ideb elevado sempre implica forte participação docente em projeto coletivo escolar, do qual são protagonistas confessos e cruciais. Políticas estaduais não são muito diversas das políticas federais, porque não estão ancoradas no chão da escola. Mas é neste que tudo se decide. O exemplo do Ceará foi emblemático: um estado nordestino que fez eclodir, por alguma motivação complexa, a energia de municípios e escolas para virar a mesa e atingir resultados não conhecidos antes. $\mathrm{O}$ próprio recuo relativo atual de Sobral indica que é, em grande parte, questão "política", já que tais iniciativas naturalmente arrefecem, cansam, viram rotina. É duro chegar lá em cima; é ainda mais duro, manter-se lá. 
Os dados insinuam então um conluio entre município e escola, que, de certo modo, à revelia das políticas "de cima" (estadual e federal), pode frutificar em projetos locais escolares capazes de uma história diversa. Na prática, a questão chave é "local", ou seja, da escola. A gerência municipal é importante, também porque está mais perto, mas a escola funciona se os docentes assim quiserem.

Esta colocação não desdenha dos níveis "superiores" de política, apenas os considera, a rigor, "inferiores", ou seja, são de suporte. Tomando concretamente: não é o caso o MEC ou o estado decidir como se faz a alfabetização até aos três anos. É muito impróprio impor instrução direta, método fônico, abordagem holista ou Paulo Freire. É o professor quem precisa ter condições técnicas suficientes para, diagnosticando a situação e cada estudante, decidir o que fazer de melhor para ele. Cabe às instâncias de suporte colaborar, investir, mas não decidir. As instâncias ditas superiores devem cobrar os resultados, não determinar os procedimentos. O alfabetizador que não consegue montar seu planejamento, diagnosticar os estudantes, elaborar sua proposta teórica e prática de alfabetização, precisa, a rigor, antes, ainda ser "alfabetizado". Cumpre, ademais, oferecer condições de trabalho adequadas ao alfabetizador. Ao final, a aposta local é uma aposta no professor, não em diretrizes que vêm de cima, dinheiro carimbado, profecias do arco da velha, retóricas celestiais. E se o estudante não aprende, nada valeu a pena.

Esta posição pode ser mal entendida, se for vista como voluntarismo local, já que muitos municípios não possuem condição mínima para tocar a escola. Mas, como é o município que a vai tocar, há que capacitar o município, técnica e financeiramente, para que resultados possam ser cobrados. Então, a ideia apenas exara um contexto concreto de federalismo consequente, não ao avesso como é uso entre nós. O MEC não se entende como suporte ao município, porque, politicamente, tende a valorizar a posição supremacista mais do que o resultado para os estudantes. Por exemplo, parece claro que a formação dos professores básicos nas universidades precisaria ser completamente refeita, reinventada. Esta seria obra urgente do MEC, mas não acontece porque universidades são entidades fortes demais para serem dobradas com facilidade. Universidades, sim, entendem o MEC como suporte! O município do fim do interior pede licença... 


\section{Considerações finais}

É, de certa forma, um alívio ver que alguns estados mais modestos no concerto nacional podem destacar-se em educação, quando conseguem arrumar-se localmente (municipalmente). Sobral foi o primeiro alerta de que um município, se quiser, pode se autoconduzir em educação, até porque autocondução é que mais bem condiz com a educação que se imagina emancipatória. Sobral reconheceu que, mesmo a disponibilidade recursos e condições mais favoráveis, isto pode ajudar, não determinaria decisão local. O município assumiu, em colaboração com os docentes que compõem, ao final, a garantia da escola. Mostrou que é possível uma escola de qualidade, mesmo que sempre venhamos a discutir o que seja esta qualidade, como aventei acima, ao questionar os resultados chineses do PISA. Mostra também que não é fácil ficar no topo. Sobral já escorregou para a $11^{\mathrm{a}}$ posição, embora continue um exemplo fundamental. Entrementes, outros estados se insinuam, com destaque para Espírito Santo e Goiás, o que indica que todo estado pode sacudir-se, se quiser. O exemplo de bons resultados no Acre também reforça a hipótese.

Afinal, aprender bem não pode ser enigma. Sendo aprendizagem autoral condição evolucionária natural, a vida é aprendizagem. A escola é que facilmente encalha em procedimentos que mais se alinham ao repasse de conteúdo curricular do que ao direito do estudante de aprender bem. Atividades de aprendizagem são relegadas (DEMO, 2018), porque na escola nos bastamos com aula, prova e repasse. Isto aprendemos na faculdade, mas é isto que nos torna profissionais do ensino totalmente insatisfatório. Os municípios precisam abrir os olhos e entender que são, até certo ponto e não linearmente, a referência maior da educação. Sempre vemos com certa ironia quando a federação alega que tudo começa no município, porque, na prática, tudo começa em Brasília e muitas vezes nem de lá sai. Mas em educação parece mais claro que soluções são, por vocação, locais.

AGRADECIMENTOS: Ao Conselho Nacional de Desenvolvimento Científico e Tecnológico- CNPQ. 


\section{REFERÊNCIAS}

\section{ANUÁRIO BRASILEIRO DA EDUCAÇÃO BÁSICA 2019. Todos pela}

Educação/Moderna. São Paulo. Disponível em:

https://www.todospelaeducacao.org.br/_uploads/_posts/302.pdf. Acesso em: 20 set. 2020.

BID. ELACQUA, G et al. Profissão professor na américa latina: por que a docência perdeu prestígio e como recuperá-lo? N.Y.: BID, 2018. Disponível em:

https://publications.iadb.org/handle/11319/8953. Acesso em: 20 set. 2020.

DEMO, P. Aprender como autor. São Paulo: Gen, 2015.

DEMO, P. Sobral está sobrando! O que Sobral tem que outros não têm? 2017.Disponível em: https://docs.google.com/document/d/1LmTbbbQMUuU49L-a8Wlei-

TdwcttStuQ4UboW2SMIlY/pub. Acesso em: 20 set. 2020.

DEMO, P. Questionando a Graduação. 2017a. Disponível em:

https://docs.google.com/document/d/1y-OhRkIY-Lb_Y2P-

0eVntZZQBY79MbPY4fSdA8TSol4/edit. Acesso em: 20 set. 2020.

DEMO, P. Atividades de Aprendizagem: sair da mania do ensino para comprometer-se com a aprendizagem do estudante. Campo Grande, MS: SED/GOV, 2018. Disponível em:

https://drive.google.com/file/d/1FKskDCxNB422PVhrjrDjD48S4cjsb77-/view. Acesso em: 20 set. 2020.

DEMO, P. Escola e Cuidado. 2019. Disponível em:

https://drive.google.com/file/d/1XKQDqJHfNMFEnN2gVF1n6yZmEmoYkS34/view. Acesso em 20 set. 2020.

DEMO, P. Educação à Deriva - À direita e à esquerda: instrucionismo como patrimônio nacional. 2020. Disponível em: https://drive.google.com/file/d/10nMlgL8N9GKFgwtnbLbIn7GQf0HdyA4/view. Acesso em: 20 set. 2020.

DEMO, P. O que resta da escola na vida. 2020a. Disponível em:

https://drive.google.com/file/d/1swMQ-4m1DKJ4Nhfa_CbxrR4upYKZLPBG/view. Acesso em: 20 set. 2020 .

FOUCAULT, M. Vigiar e punir. História da violência nas prisões. Petrópolis: Vozes, 1977.

HORN, J.; WILBURN, D. The mismeasure of education. IAP, Charlotte, 2013.

RIPLEY, A. The Smartest Kids in the World: And How They Got That Way. N.Y.:

Simon \& Schuster, 2013

RUSSAKOFF, D. The prize: who's in charge of america's schools? N.Y.: Houghton Mifflin Harcourt, 2015.

SAHLBERG, P. FinishED leadership. Thousand Oaks: Corwin, 2017. 
SCHLEICHER, A. PISA 2018 - Insights and Interpretations. Paris: OECD Publishing, 2019. Disponível em:

https://www.oecd.org/pisa/PISA\%202018\%20Insights\%20and\%20Interpretations\%20FINAL \%20PDF.pdf. Acesso em: 20 set. 2020.

ZHAO, Y. Who is afraid of the big bad dragon: why China has the best (and the worst) education system in the world? San Francisco: Jossey-Bass, 2014.

ZHAO, Y. What works may hurt. Side effects in education. Teachers College Press, 2018.

\section{Como referenciar este artigo}

DEMO, P.; SILVA, R. A. Sinalizações das escolas e municípios no contexto do IDEB 2019: tentativa preliminar de leitura do IDEB-2019. Temas em Educ. e Saúde, Araraquara, v. 16, n. 2, p. 630-647, jul./dez. 2020. e-ISSN 2526-3471. ISSN 1517-7947. DOI: https://doi.org/10.26673/tes.v16i2.14210

Submetido em: 03/04/2020

Revisões requeridas: 28/06/2020

Aprovado em: 31/07/2020

Publicado em: 27/08/2020 